\title{
The Dishevelled protein is modified by Wingless signaling in Drosophila
}

\author{
Shin-ichi Yanagawa, ${ }^{1,2}$ Frank van Leeuwen, ${ }^{1,3}$ Andreas Wodarz, John Klingensmith, ${ }^{4}$ and Roel \\ Nusse $^{5}$ \\ Howard Hughes Medical Institute, Department of Developmental Biology, Beckman Center, Stanford University, Medical \\ Center, Stanford, California 94305-5428 USA
}

\begin{abstract}
Wingless $(\mathrm{Wg})$ is an important signaling molecule in the development of Drosophila, but little is known about its signal transduction pathway. Genetic evidence indicates that another segment polarity gene, dishevelled $(d s h)$ is required for $\mathbf{W g}$ signaling. We have recently developed a cell culture system for $\mathbf{W g}$ protein activity, and using this in vitro system as well as intact Drosophila embryos, we have analyzed biochemical changes in the Dsh protein as a consequence of $\mathrm{Wg}$ signaling. We find that Dsh is a phosphoprotein, normally present in the cytoplasm. Wg signaling generates a hyperphosphorylated form of Dsh, which is associated with a membrane fraction. Overexpressed Dsh becomes hyperphosphorylated in the absence of extracellular $\mathrm{Wg}$ and increases levels of the Armadillo protein, thereby mimicking the Wg signal. A deletional analysis of Dsh identifies several conserved domains essential for activity, among which is a so-called GLGF/DHR motif. We conclude that $d s h$, a highly conserved gene, is not merely a permissive factor in Wg signaling but encodes a novel signal transduction molecule, which may function between the $\mathrm{Wg}$ receptor and more downstream signaling molecules.
\end{abstract}

[Key Words: Dishevelled protein; wingless signaling; Drosophila development; signal transduction]

Received February 10, 1995; revised version accepted March 21, 1995

Over the past few years, it has become clear that signaling proteins and the hierarchies in which they operate are highly conserved in evolution /for review, see Greenwald and Rubin 1992; Egan and Weinberg 1993; Sternberg 1993). The use of genetics in organisms such as yeast, Caenorhabditis elegans, or Drosophila may therefore provide a good system to dissect a signaling pathway, particularly when a biochemical approach is difficult.

This situation applies to the case of Wnt signaling. Wnt genes encode secreted molecules with potent effects on cells, either during tumorigenic transformation or during normal development, but the mechanism of Wnt signal transduction has been difficult to study because of the lack of suitable in vitro systems (Nusse and Varmus 1992). Wnt genes are highly conserved in evolution and include the Drosophila gene wingless (wg), which is the ortholog of the mouse Wnt-1 gene (Rijsewijk et al. 1987). wg encodes a signaling molecule $(\mathrm{Wg})$ that is involved in cell-cell communication during many phases of embryonic and adult pattern formation (Baker 1988; Cohen

\footnotetext{
${ }^{1}$ The first two authors made equal contributions to this paper. Present addresses: ${ }^{2}$ Department of Viral Oncology, Institute for Virus Research, Kyoto University, Kyoto, Japan; ${ }^{3}$ Department of Cell Biology, Netherlands Cancer Institute, Amsterdam, The Netherlands; ${ }^{4}$ Samuel Lunenfeld Research Institute, Mount Sinai Hospital, Toronto, Ontario M5G 1X5, Canada.

${ }^{5}$ Corresponding author.
}

1990; Bejsovec and Martinez-Arias 1991; Dougan and Dinardo 1992; Struhl and Basler 1993; Kaphingst and Kunes 1994). The early embryonic phenotype of the wg mutation, a segment polarity defect, is shared with a number of other so-called segment polarity mutants, suggesting that these genes are part of a common pathway. In particular, porcupine (porc), dishevelled (dsh), and armadillo (arm) have embryonic phenotypes identical to that of wg (Perrimon and Mahowald 1987; Klingensmith et al. 1989).

By a combination of genetic epistasis and clonal analysis experiments, the order in which these genes act has been established. porc seems to be required for Wg protein secretion (van den Heuvel et al. 1993; Siegfried et al. 1994), whereas in the receiving cell, $d s h$ is the earliest acting known component of the $\mathrm{Wg}$ signaling pathway (Klingensmith et al. 1994; Noordermeer et al. 1994; Siegfried et al. 1994). Downstream of $d s h$ is a gene called zeste white $3(z w 3)$ or shaggy, encoding a serine/threonine kinase (Bourouis et al. 1990; Siegfried et al. 1990) that negatively regulates $\mathrm{arm}$. Signaling by $\mathrm{Wg}$ relieves this inhibitory function of zw-3 (Siegfried et al. 1992; Diaz-Benjumea and Cohen 1994/ resulting in the accumulation of the Arm protein, which mediates many downstream effects of $w g$, (Riggleman et al. 1990; Peifer et al. 1994b). Dsh, Arm, Porc, and Zw3 are maternally provided in the egg, so that embryonic phenotypes are only seen when both maternal and zygotic products are eliminated (Klingensmith and Perrimon 1991). 
On the basis of these genetic interactions (for review, see Klingensmith and Nusse 1994; Perrimon 1994), Dsh appears to be essential for Wg signaling. Dsh RNA is ubiquitous in embryonic epithelial cells and imaginal discs, and the gene is essential for Wg signal transduction in both of these tissues. The deduced amino acid sequence of Dsh predicts a protein of $\sim 70 \mathrm{kD}$ (Klingensmith et al. 1994; Theisen et al. 1994). The absence of a signal peptide or transmembrane domains suggests that Dsh is an intracellular protein, but its location has not been studied. Although the Dsh protein has little similarity with any known protein, one domain, $\sim 60$ amino acids long, shows homology to a repeated sequence known as the GLGF repeat or discs-large homology region (DHR) (Bryant and Woods 1992; Cho et al. 1992). This motif is found in a number of other proteins, most of which are thought to be associated with cell junctions, including the protein encoded by the Drosophila tumor suppressor gene discs-large (Woods and Bryant 1991). $d s h$ is highly conserved in evolution: A number of $d s h$ homologs in vertebrates have been isolated. A sequence comparison between $d s h$ and the mouse $d s h$ gene $D v l-1$ shows an overall $50 \%$ identity at the amino acid level with almost complete conservation of the GLGF/DHR domain (Sussman et al. 1994).

The identification of $d s h$ is a good example of the power of Drosophila to find genetic components in signaling pathways. Nevertheless, it does not become clear from these epistasis experiments whether $d s h$ has a general permissive function or plays an active role as a signaling molecule. Moreover, there has been no biochemical analysis of the Dsh protein. In general, the possibilities for analyzing signaling events in cell culture have been limited in Drosophila, and the biochemical functions of Drosophila signaling genes have therefore often been inferred from their mammalian counterparts. Such cell culture assays are indispensable to study, for example, the kinetics of signaling events. But in the case of Wnt signaling, no suitable in vitro assays for mammalian Wnt proteins have been available. Recently, however, we have developed a cell culture assay for $\mathrm{Wg}$ activity, using a cell line (cl-8) from Drosophila imaginal discs (Van Leeuwen et al. 1994). With this assay, we demonstrated that extracellular Wg protein is able to elevate levels of the Arm protein rapidly, involving changes in the phosphorylation status and stabilization of the Arm protein.

In this work we analyze the function of Dsh in Wg signaling. We show that Dsh becomes hyperphosphorylated in response to extracellular $\mathrm{Wg}$. We also find that overexpression of Dsh in the absence of $\mathrm{Wg}$ leads to an increase in Arm levels, providing us with an assay for Dsh function. Through a deletion analysis of the Dsh cDNA and transfection into cl-8 cells, we show the importance of the GLGF/DHR domain for Dsh activity.

\section{Results}

\section{Antibodies specific for the Dsh protein}

To characterize the Dsh protein, we raised antisera to fusion proteins containing different domains of Dsh. The positions of these domains are indicated in Figure $6 \mathrm{E}$. The amino-terminal domain (region I) was fused to the bacterial GST-protein and used to raise antisera in rats. A large internal domain of Dsh (region II) was fused to $\operatorname{trp} E$ and used to immunize rabbits.

Figure 1A shows that in lysates of Drosophila embryos or the Drosophila imaginal disc cell line cl-8, the rat antiserum against Dsh region I reacts with several protein species of $\sim 70 \mathrm{kD}$, corresponding to the predicted size of the primary translation product of $d s h(68850.50$ Daltons (Klingensmith et al. 1994). To show that these species were the product of the $d s h$ gene, we performed an immunoprecipitation with the rabbit antiserum against region II and then analyzed the precipitated material by Western blot, using the anti-region I serum. We found the same species reacting (Fig. 1B). Because region I and II do not overlap, this experiment demonstrates that the reaction of the antibodies with the two $70-\mathrm{kD}$ proteins is specific.

Additional evidence for the specificity of these antisera was obtained by comparing whole cell lysates of Drosophila wild-type embryos with those of homozygous mutants carrying the $d s h^{V 26}$ allele. This allele has undergone a gene-internal deletion that has not been mapped exactly but takes out at least part of the proteinencoding domain of $d s h$ (Klingensmith et al. 1994).



Figure 1. Antibodies raised against Dsh specifically recognize the Dsh protein in cl-8 cells and wild-type embryos but not in Dsh mutant embryos. $(A)$ Western blot of embryo or cl-8 cell lysates, using the anti-region I rat antiserum. $|B|$ Immunoprecipitation from embryo or cl-8 cell lysates, using the anti-region II rabbit antiserum, followed by Western blotting using antiregion I rat antibodies. The cross-reacting bands around $55 \mathrm{kD}$ are caused by the primary antibody reacting with the abundant immunoglobulin molecules. $(C)$ Western blot comparing lysates of wild-type embryos with embryos homozygous mutant for the $d s h^{V 26}$ allele, using the rat anti-region I antibody. The smaller cross-reacting protein species are not specific for Dsh and most likely represent chorion proteins, abundantly present in these preparations. 
When a collection of embryos mutant for $d s h$ (derived from germ-line clones carrying the $d s h^{\text {V26 }}$ allele) was analyzed, the $70-$ to $80-\mathrm{kD}$ species were absent, whereas wild-type embryos did contain these proteins (Fig. 1C). No novel smaller forms of Dsh were detected in $d s h^{\text {V26 }}$ embryos, but these could have been masked by other proteins.

In extracts of cultured cells and embryos, additional protein species were detected by the anti-region I antiserum. These could be either the products of Dsh-related genes or nonspecifically cross-reacting proteins and were ignored in the subsequent experiments.

\section{In embryos and in cultured cells, Dsh is a cytoplasmic protein}

We examined the cellular distribution of the Dsh protein by immunostaining methods, using the rat anti-region I serum. In whole-mount Drosophila embryos around cellular blastoderm, when the cells form a single-layered epithelium at the periphery of the embryo, the antibody revealed a cytoplasmic staining pattern (Fig. 2A). The apical side of the cells stained more intensely than basal regions (Fig. 2B). Later, around gastrulation, Dsh staining was uniform, except for areas with a high cell density such as the proctodeum (Fig. 2C,D). During the extended germ-band stage, the protein was also uniformly distributed, with no discernible regional or segmental differences (Fig. 2E,F). In particular, there were no changes in Dsh distribution within the area of $\mathrm{Wg}$ expression (Fig. 2E). During all of these stages, the Dsh protein appeared to be cytoplasmic, although at later stages a more punctate pattern was also seen (Fig. $2 \mathrm{H}$ ).

To control for the specificity of the antibody reaction, we stained a collection of embryos lacking the Dsh gene product. Apart from some large positively staining dots that were not seen in wild-type embryos and may represent dead cells, no cytoplasmic staining was apparent (Fig. 2I). We examined a number of other Drosophila tissues, including wing imaginal discs, and found a similar distribution of the Dsh protein (not shown). In the cl-8 imaginal disc cell line, Dsh is also cytoplasmic (Fig. 2J).

\section{In cl-8 cells and in intact embryos, Dsh is phosphorylated in response to $\mathrm{Wg}$}

To analyze possible biochemical consequences of $\mathrm{Wg}$ signaling with respect to the Dsh protein, we used the in vitro system for $\mathrm{Wg}$ activity that we established recently (Van Leeuwen et al. 1994). In these assays, cl-8 imaginal disc cells are cultured in medium conditioned by Schneider 2 cells overexpressing the heat shock-inducible $\mathrm{Wg}$ protein (S2-HS-wg) or cocultured with those cells. cl-8 cells respond to $\mathrm{Wg}$ by an increase in the intracellular concentration of the Arm protein (Van Leeuwen et al. 1994).

When we compared the Dsh protein in naive cl-8 cells with those that had been cultured in the presence of the $\mathrm{Wg}$ protein, we found additional, slower migrating forms of Dsh in the Wg-stimulated cells. (Fig. 3A). In response
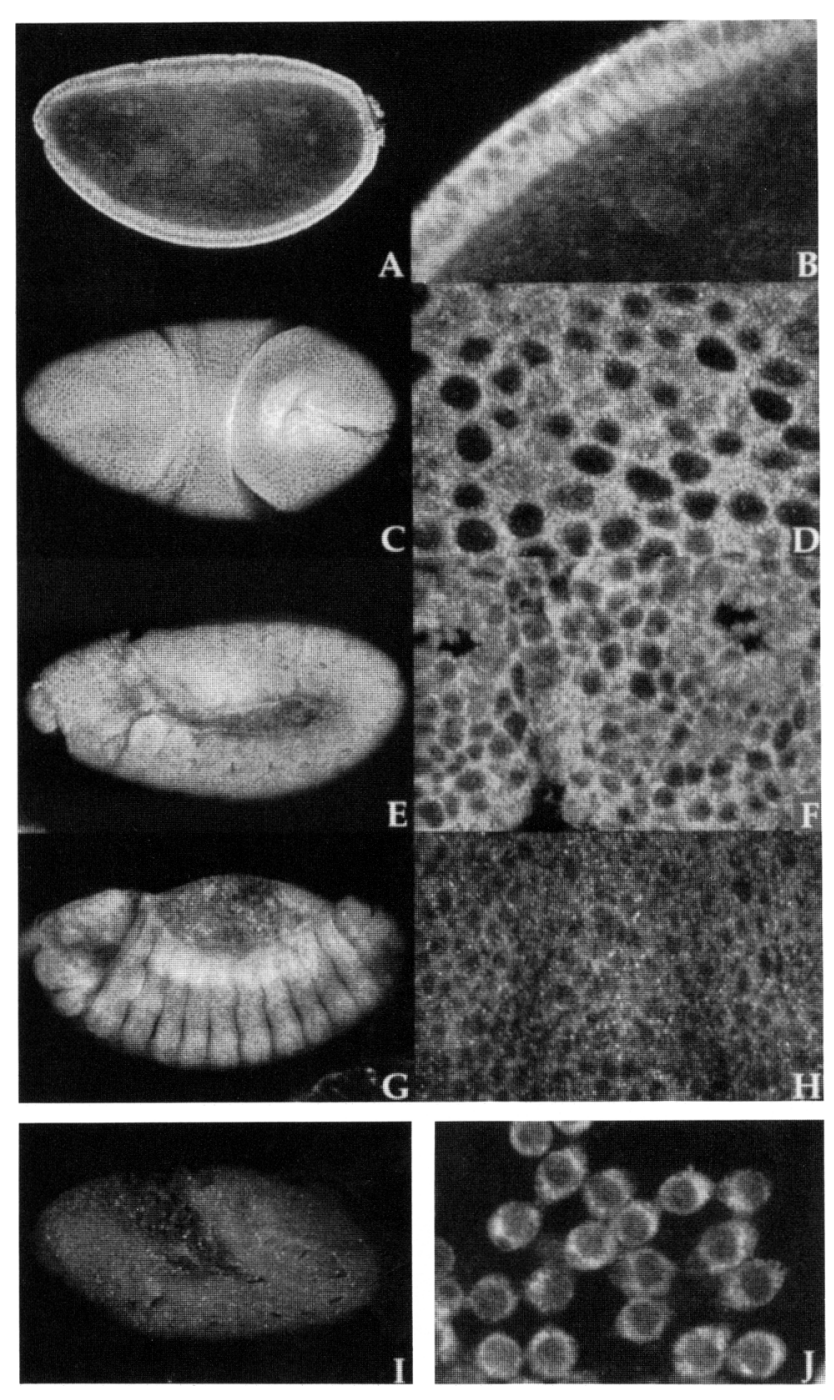

Figure 2. Localization of Dsh during embryonic development and in cl-8 imaginal disc cells. Confocal micrographs are shown. $|A, B|$ Cellular blastoderm, stage 5 . Dsh is visible in the cytoplasm with a slightly higher amount of protein in the apical region of the cells. $(C, D)$ Gastrulation, stage 7. Dsh staining is clearly absent in the nucleus. $(E, F)$ Extended germ band, stage 11. Note the uniform staining pattern without any segmentally repeated stripes. $(G, H)$ End of germ-band retraction, stage 13 . Cytoplasmic dots can be seen at later stages of development. $(I)$ A $d s h^{v 26}$ mutant embryo derived from a germ-line clone. Only weak background staining is visible. The bright spots scattered over the embryo are artifacts that can also be seen in stainings with several other antisera that are not directed against Dsh and might represent debris of dead cells. (J) The endogenous Dsh of cl-8 cells is localized in the cytoplasm. $(A-I)$ Embryos are oriented with the anterior to the left and, except for $C$ and $D$, dorsal side up. $(C, D)$ Views from the dorsal side. Except for $I$, images in the right panel are close-up views of the embryos displayed in the left panel. The plane of focus in $C, I$ is close to the apical surface of the epidermis, whereas $A$ and $B$ are optical sagittal sections close to the middle of the embryo. Staging of embryos is according to Campos-Ortega and Hartenstein (1985). 
A
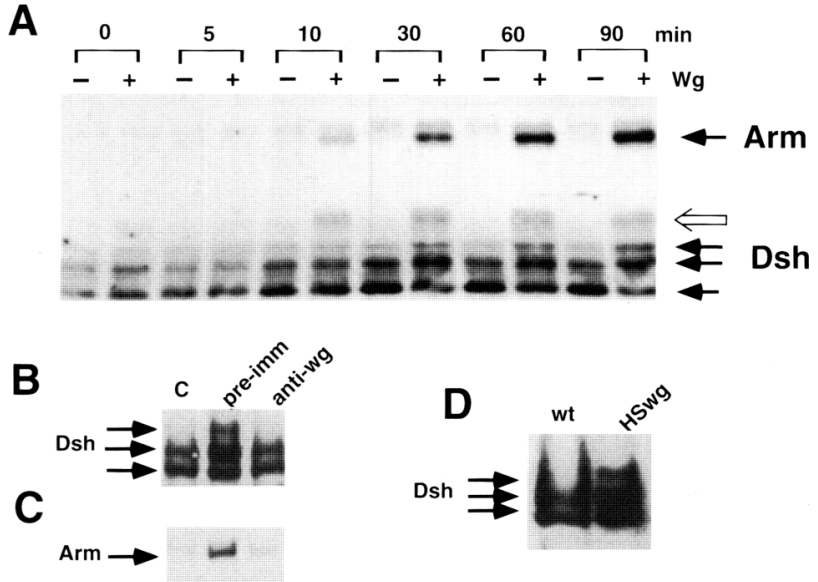

Figure 3. Dsh is modified in response to $\mathrm{Wg}$, both in cl- 8 cells and in vivo. $(A)$ Western blot showing the Arm and Dsh protein in lysates of cl-8 cells cocultured with S2-HS-wg cells $(+)$ or control S2 cells $(-\mid$ for different time intervals. An additional, more slowly migrating form of Dsh (open arrow) is detectable after $10 \mathrm{~min}$ of $\mathrm{Wg}$ incubation. The filter was probed at the same time with the anti-Arm antibody. An increase in Arm protein levels is seen after 10 min of incubation with $\mathrm{Wg}$, and levels increase further over time. (B) Inhibition by the anti-Wg antibody. Western blot showing the Dsh protein in lysates of $\mathrm{cl}-8$ cells that were not stimulated (lane $C$ ), or incubated for $2 \mathrm{hr}$ with medium conditioned by S2-HS-wg cells. Medium was conditioned by S2-HS-wg cells, concentrated 10-fold, and preincubated for $1 \mathrm{hr}$ with $\mathrm{Wg}$ antiserum or a preimmune serum, before adding to the cl-8 cells. The $\mathrm{Wg}$ antiserum, but not the preimmune serum, prevents the appearance of the slower migrating Dsh species. $(C)$ Arm levels in the same samples were determined, which demonstrates that the anti- $\mathrm{Wg}$ antiserum, but not the preimmune serum, depleted $\mathrm{Wg}$ activity from the medium. (D) Dsh protein in lysates of wild-type embryos or HS-wg embryos, determined by Western blotting. Both wildtype and HS-wg embryos were heat-shocked for $30 \mathrm{~min}$ at $37^{\circ} \mathrm{C}$ and allowed to recover for $3 \mathrm{hr}$ before lysates were made. In the embryos overexpressing $\mathrm{Wg}$, modified forms of Dsh are detected.

to $\mathrm{Wg}$, Arm protein levels increased concomitantly with the modification of the Dsh protein (Fig. 3A). To control for the amount of protein loaded in each lane we used an antibody against $\alpha$-catenin, a protein with levels that are unaffected by Wg (Oda et al. 1993; data not shown). We could show that the modification of Dsh (and the Arm accumulation/ was dependent on active $\mathrm{Wg}$ protein, because preincubation of the Wg-conditioned medium with a Wg-specific antibody, but not a preimmune antiserum, could block these effects (Fig. 3B,C).

To test whether Wg expression in vivo would also lead to modification of Dsh, we used a Drosophila strain carrying a heat shock-inducible wg transgene (HS-wg), shown previously to display a variety of $w g$-dependent effects that are mediated by Dsh (Noordermeer et al. 1992). In lysates of HS-wg embryos, an increase in Dsh modification was observed $3 \mathrm{hr}$ after heat shock (Fig. 3D).
To examine the nature of the Dsh modification, Dsh immunoprecipitates obtained from lysates of Wg-stimulated cl-8 cells or from embryos were treated with potato acid phosphatase (PAP). After incubation, immunoreactive Dsh migrated as a single species (Fig. 4). Treatment with recombinant protein tyrosine phosphatase (PTP) did not affect the various modified forms. In addition, immunoprecipitation of cell or embryo lysates with the Dsh antibody, followed by Western blotting with antiphosphotyrosine antibodies, did not reveal a specific reaction (results not shown).This suggests that Dsh is modified by serine/threonine phosphorylation and that $\mathrm{Wg}$ treatment of cells results in additional phosphorylation on these residues.

\section{A change in subcellular distribution of Dsh in fractionated cell extracts}

We have looked for $\mathrm{Wg}$-induced changes in the subcellular location of the Dsh protein by the immunostaining of cl-8 cells before and after incubation with $\mathrm{Wg}$, or staining HS-wg embryos, yet no changes were detected (not shown). We then used cell fractionation methods as a more sensitive assay by which to examine Dsh distribution. Cells were fractionated by differential centrifugation into a soluble fraction containing cytoplasmic components and a membrane fraction containing plasma membrane and membranous organelles. The distribution of the Arm protein was a useful marker for the efficiency of the fractionation (Fig. 5A). Peifer et al. $(1994 a, b)$ have shown that in response to the $\mathrm{Wg}$ signal in vivo, the cytoplasmic pool of the Arm protein increases, whereas the membrane-bound form of Arm is less affected. In naive cl-8 cells, Arm protein was present as two differently migrating forms, which is the result of differences in phosphorylation (Peifer et al. 1994a; Van Leeuwen et al. 1994). Both forms were associated almost exclusively with the membrane fraction. In the cells that had been exposed to the Wg protein, a dramatic increase in the faster migrating (underphosphorylated) form of

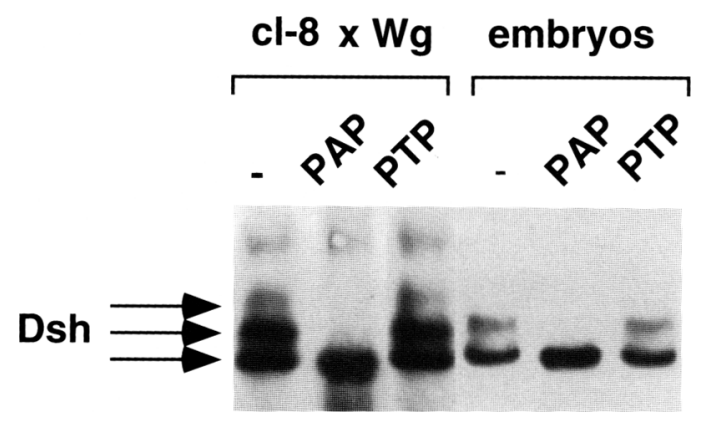

Figure 4. Dsh is a phosphoprotein. Dsh immunoprecipitates from lysates of Wg-stimulated cl-8 cells or embryonic extracts were treated for $2 \mathrm{hr}$ with buffer alone $1-1$, PAP, PTP. In both cl-8 cells and in embryos, PAP treatment resulted in a single Dsh species, whereas PTP did not, showing that Dsh is phosphorylated but not on tyrosine residues. 


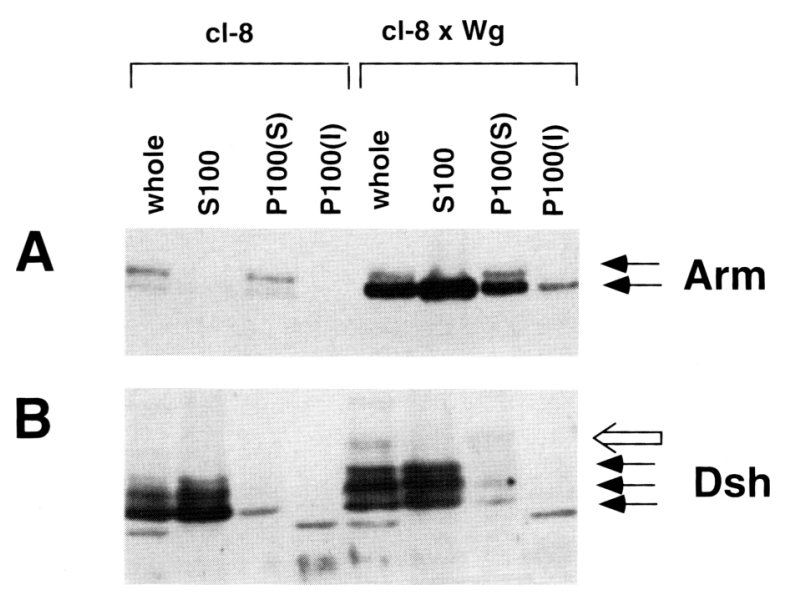

Figure 5. Subcellular distribution of Arm and Dsh protein in naive cl-8 cells and cells stimulated with Wg. Fractionation and characterization of soluble and pelletable forms of Arm and Dsh in nonstimulated cl-8 cells (left), and cells cocultured with Wgexpressing S2 cells (right). Cell material was separated into a soluble $(\mathrm{S} 100)$ fraction, an NP-40 soluble membrane fraction [P100(S)] and an NP-40 insoluble membrane fraction [p 100(I)]. (A) Arm protein distribution in nonstimulated cl-8 cells and Wg-stimulated cl-8 cells. $(B)$ Dsh protein distribution in the same fractions. The open arrow indicates the hyperphosphorylated form of Dsh.

Arm was seen in the soluble cytoplasmic fraction and, to a much lesser extent, in the membrane fraction. The slower migrating (phosphorylated) form of Arm, detectable only in the membrane fraction, was not affected by $\mathrm{Wg}$.

In naive cl- 8 cells, we found most of the Dsh protein in the cytoplasmic fraction, in agreement with the staining results, although small amounts were also present in the membrane fraction (Fig. 5B). The cells incubated with the $\mathrm{Wg}$ protein showed an overall increase in the amount of phosphorylation of Dsh. In addition, a significant fraction of the phosphorylated forms was present in the membrane fraction of Wg-exposed cl-8 cells. In particular, the hyperphosphorylated (slowest migrating) Dsh species was present in the membrane fraction only.

\section{Overexpressed Dsh is modified and elevates}

Arm levels

Overexpression of an intracellular component of a signal transduction pathway is often able to bypass the need for an extracellular stimulus. To examine whether this could be achieved with Dsh, we transfected cl-8 cells with expression constructs driven by the inducible metallothionein promoter. Treatment of these cells with $\mathrm{CuSO}_{4}$ led to a considerable increase (at least 20-fold) in the amount of Dsh protein, compared with endogenous levels (Fig. 6A). Concomitantly with the increase in Dsh protein levels, an increase in Arm levels was seen (Fig. 6C). Moreover, overexpressed Dsh migrated as several different species, similar to those seen in untransfected cl-8 cells exposed to extracellular Wg protein. Analysis with phosphatases showed that these forms of Dsh had undergone phosphorylation similar to that caused by extracellular Wg (not shown), which, in conjunction with the elevation of Arm, indicates that overexpression of Dsh mimics Wg signaling.

\section{A deletional analysis of Dsh}

Having a functional assay for the Dsh protein in cl-8 cells, we made a series of Myc-tagged deletion mutants to map functional regions in the protein. As landmarks for these deletions, we used domains that are conserved between the Drosophila $d s h$ and a mouse $d s h$ homolog (Fig. 6E; Klingensmith et al. 1994; Sussman et al. 1994; Theisen et al. 1994). These included one deletion removing the GLGF/DHR domain and another one removing a conserved highly basic domain. Figure $6 \mathrm{~B}$ shows that the various deleted forms were all detectable with the antiMyc antibody, and that they were all inducible with $\mathrm{CuSO}_{4}$, albeit to different levels. Two deletions removing carboxy-terminal regions of the Dsh protein had no effect on the elevation of Arm (Fig. 6B,D). One of these removes a nonconserved part of the protein, whereas the other takes out a significant portion of a conserved domain (Fig. 6E). However, deleting additional conserved sequences produced inactive forms of Dsh, as indicated by their failure to induce Arm protein accumulation. The internal deletion of the GLGF/DHR domain showed that this portion is essential for function, but the basic domain proved to be dispensable (Fig. 6B,D).

Importantly, there is an absolute correlation between activity in the Arm assay and hyperphosphorylation of Dsh and vice versa. For example, the deletion mutant lacking the basic region (D-br) became modified (by phosphorylation as it is sensitive to phosphatase; data not shown) and was active on Arm. Conversely, the GLGF/DHR deleted form (D-dhr) was made at high levels after induction with $\mathrm{CuSO}_{4}$, but the protein migrated as a single species. This suggests that the hyperphosphorylated forms of Dsh, generated by either overexpression or by $\mathrm{Wg}$ stimulation, are the active forms.

Wg does not modify Dsh or Arm in S2 cells, but overexpression of Dsh in $S 2$ cells increases Arm levels

To corroborate the evidence that Dsh modification is a specific response to the $\mathrm{Wg}$ signal, we examined another Drosophila cell line, S2. We had observed previously that $\mathrm{S} 2$ cells do not respond to extracellular $\mathrm{Wg}$, that is, Arm levels are not affected. Accordingly, in S2 cells overexpressing $\mathrm{Wg}$ after transfection of a heat shock promoterdriven $\mathrm{Wg}$ construct, levels of the Arm protein are unchanged (Fig. 7B).

When we examined Dsh in S2 cells, we found that the protein migrated as a single species. Even in S2 cells overproducing the $\mathrm{Wg}$ protein, no modification of Dsh could be detected (Fig. 7A). However, when we generated S2 cells overexpressing Dsh by transfection, we found that overexpressed Dsh was modified and gave rise to a 
Figure 6. Overexpression of Dsh elevates Arm levels; a deletional analysis of the Dsh protein. $(A)$ Overexpression of Dsh at various time points after induction with $\mathrm{CuSO}_{4}$ as detected with the anti-region I antibody. Note the additional, hyperphosphorylated species. $(B)$ Myc-tagged variants (see $E$ ) of the Dsh cDNA were transfected into cl-8 cells under control of the metallothionein promoter. Cells were noninduced $(-)$ or induced with $\mathrm{CuSO}_{4}$ $(+1$, and Dsh species were detected by Western blotting using a myc antibody. $\mid B$ (right) was on a different gel. $\{C, D\rangle$ Arm protein levels were determined in the same samples as shown in $A$ and $B$, with the corresponding lanes above. $(E)$ Schematic representation of the Dsh protein. Regions I and II, used to generate fusion proteins for antibody production, are indicated (top). Shaded boxes represent domains of the Dsh protein that are conserved between mouse and Drosophila. The positions of the basic region and the GLGF/DHR domain are shown. A series of $d s h$ deletion mutants, each carrying a carboxy-terminal Myc epitope, are shown. Drawings represent the predicted protein lengths of these deletion constructs. Activity of the protein mutants in the Arm assay are indicated by $a+$.

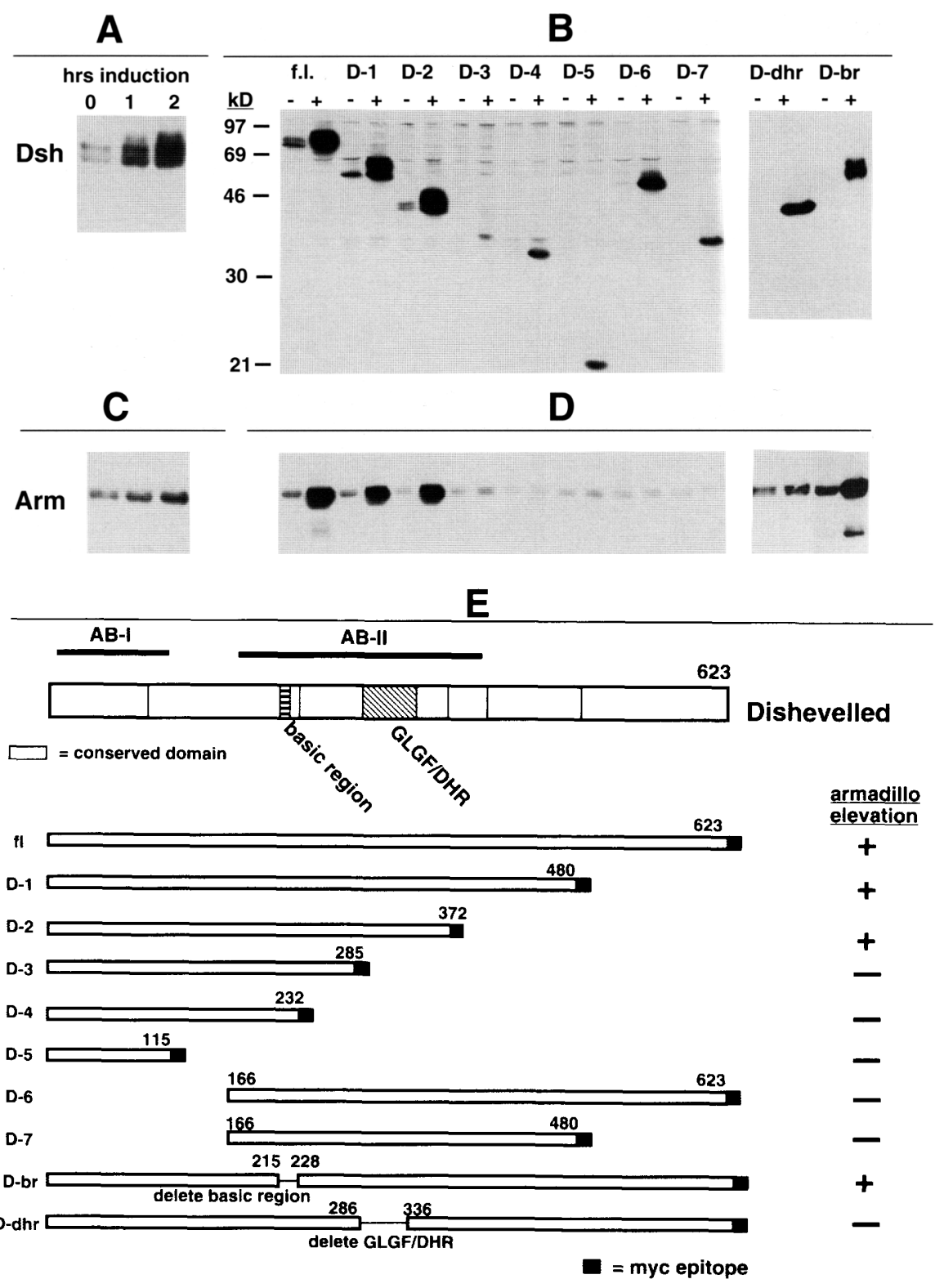

considerable increase in Arm levels (Fig. 7 C,D). Hence, $\mathrm{S} 2$ cells are refractory to extracellular $\mathrm{Wg}$, both with respect to Dsh modification and Arm stabilization, but overexpression of Dsh, an intracellular component of the Wg signaling pathway, overcomes this defect and bypasses the need for Wg.

\section{Discussion}

In Drosophila, a genetic approach has been taken to identify $\mathrm{Wg} / \mathrm{Wnt}$ signaling components (Klingensmith and Nusse 1994; Perrimon 1994), but most of the genes found this way encode proteins without a known signaling function. Hence, little biochemical insight into $\mathrm{Wg}$ signaling has been provided, necessitating an in vitro ap- proach. In this work we have sought to find biochemical evidence for the role of Dsh, using a cell culture assay for Wg protein activity as well as intact Drosophila embryos.

We find that extracellular $\mathrm{Wg}$ leads to increased phosphorylation of Dsh. For a number of reasons, we consider it likely that the hyperphosphorylated Dsh is an active form of the protein. First, overexpression of Dsh itself, in the absence of extracellular $\mathrm{Wg}$, leads to hyperphosphorylated forms of Dsh and to an increase in Arm level. Those deletion mutants of Dsh that are not active in the Arm assay are not modified. Second, we notice that Dsh is not modified in S2 cells, which is consistent with the lack of response of $\mathrm{S} 2$ cells to the Wg signal. In addition, the hyperphosphorylated Dsh species shows a different intracellular distribution. Whereas the protein is nor- 


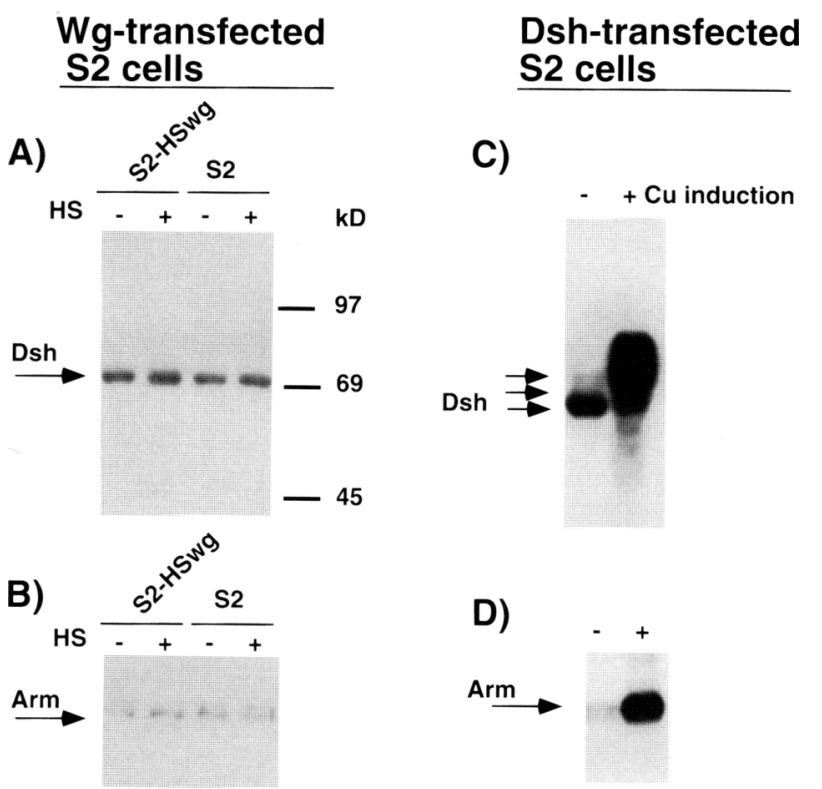

Figure 7. Drosophila $\mathrm{S} 2$ cells do no respond to $\mathrm{Wg}$, but Dsh overexpression leads to Arm elevation. (A) The Dsh protein migrates as a single species in normal and in Wg-overexpressing S2 cells. (B) Arm levels are the same in normal and Wg-overexpressing S2 cells. $(C)$ Cells overexpressing Dsh under the control of the metallothionein promoter were induced with $\mathrm{CuSO}_{4}$ showing overexpression and modification of Dsh. (D) Elevation of Arm protein levels in Dsh-overexpressing S2 cells.

mally mainly cytoplasmic, the hyperphosphorylated form appears to be associated with membranes.

These findings are reminiscent of molecular changes in other signaling pathways. A number of signaling molecules are activated when translocated to the plasma membrane. By constructing forms of these proteins that are constitutively attached to the plasma membrane, they become active in the absence of extracellular stimulation (Aronheim et al. 1994; Stokoe et al. 1994). In addition, overexpression of components in the tyrosine kinase pathway can lead to activation of downstream substrates, without activation of the upstream receptor (for review, see McCormick 1993). For example, overexpression of Grb2, a protein with no apparent enzymatic activity, potentiates growth factor signaling by recruiting Son of sevenless to the membrane, allowing this complex to interact with activated receptor tyrosine kinases and Ras (Gale et al. 1993). These effects are presumably caused by increasing concentrations of the effector, driving it in a complex with other proteins that normally only associate after activation of the receptor. On the basis of these observations and parallels with other pathways, a likely scenario for the action of the Dsh protein is that it is present in a soluble form in the cytoplasm, in various nonphosphorylated and phosphorylated forms. Signaling by Wg leads to additional phosphorylation and translocation of Dsh to an unidentified membrane component, and the protein becomes active in signal transduction. In this model we have to take into account that most of the Dsh protein is still cytoplasmic and that a minor fraction is associated with membranes. But although this membrane fraction is quantitatively a minor one, it is qualitatively different from the cytoplasmic forms, as it is hyperphosphorylated. It is very possible that the hyperphosphorylated Dsh has a dramatically different activity, possibly catalytic, compared with the cytoplasmic forms.

The modification of Dsh suggests the existence of an upstream serine/threonine kinase, which is coupled to or part of the $\mathrm{Wg}$ receptor. The identity of the protein kinase is not clear; preliminary in vitro kinase experiments suggest that it is not Zw3/Shaggy (K. Willert, F. van Leeuwen and R. Nusse, unpubl.), which would be consistent with the genetic evidence that this enzyme is downstream of Dsh (Siegfried et al. 1994). Overexpression of Dsh in S2 cells, which are not responsive to extracellular $\mathrm{Wg}$, still leads to hyperphosphorylation of Dsh and to a significant increase in Arm levels. S2 cells may lack a component of $\mathrm{Wg}$ signaling that is upstream of Dsh, possibly the receptor for $\mathrm{Wg}$.

In intact Drosophila embryos carrying a HS-wg transgene (Noordermeer et al. 1992), we find a similar modification of the Dsh protein when wg expression is ubiquitously induced at high levels. The longer lag time in vivo probably reflects the time required for synthesis and folding of active $\mathrm{Wg}$ protein and is similar to the minimal time required to induce ectopic expression of engrailed (Noordermeer et al. 1992). In wild-type embryos, we normally do not detect the hyperphosphorylated Dsh species, which may be attributable to the low levels of Wg present in these embryos relative to the HS-wg embryos.

A structure-function analysis of the Dsh protein reveals the importance of domains that are conserved between mouse and Drosophila. Most importantly, a relatively small deletion affecting the GLGF/DHR domain results in a protein that is no longer phosphorylated and is inactive in the Arm assay. It is not clear what the function of the GLGF/DHR domain is. It has been suggested that this region, which is present in a number of junctional proteins, would target proteins to the membrane or to junctional complexes. However, we find that Dsh is mainly a cytoplasmic protein, but it is possible that the GLGF/DHR repeat is involved in the regulated translocation of Dsh to the membrane by $\mathrm{Wg}$ activity.

The in vitro consequences of $\mathrm{Wg}$ on cultured cells reemphasize the important role of the Arm protein in $\mathrm{Wg}$ signaling. Both extracellular $\mathrm{Wg}$ and overexpression of intracellular Dsh lead to a significant increase in the concentration of the Arm protein. The cell fractionation studies shown in this paper and by Peifer et al (1994) show that the accumulation of Arm is mainly attributable to an increase in the cytoplasmic, soluble pool of Arm, rather than the membrane-associated fraction. Moreover, it is the hypophosphorylated form of Arm that increases in steady-state levels, in agreement with the postulated inhibitory role of the kinase $\mathrm{Zw} 3$ and the release of this inhibition through $\mathrm{Wg}$ signaling. These findings indicate that cytoplasmic Arm, being subject to 
highly dynamic forms of regulation, may have functions that are not related to adherens junctions or to cell adhesion. Cytoplasmic Arm could be part of a complex including other $\mathrm{Wg}$ effectors The recent finding that its mammalian homolog $\beta$-catenin is associated with the human tumor suppressor gene product adenomatous polyposis coli (APC) (Rubinfeld et al. 1993; Su et al. 1993) underscores the potential importance of these molecules as growth regulators. We have now shown that Dsh, a highly conserved protein, is biochemically upstream of Arm in Drosophila cells, corroborating the genetic evidence on the relationship between these genes and suggesting that a similar pathway exists in vertebrate cells. This modification of Dsh is the second known molecular effect brought about by a Wnt protein in vitro, next to the elevation of the Arm protein. Because Dsh acts early in Wg signaling, molecular changes in this molecule may provide important parameters in the search for the $\mathrm{Wg}$ receptor.

\section{Materials and methods}

Expression constructs

A 10-amino-acid sequence, derived from the human c-Myc protein, (EQKLISEEDL) (Evan et al. 1985) was added to the carboxyl termini of full-length and mutant forms of the Dsh protein. To achieve this, a derivative of pBluescript IIKS + , referred to as pBSII-myc, was constructed. Specifically, a 76-bp doublestranded oligonucleotide $15^{\prime}$-GGATCCCGCACTAAACCATGGACGAATTCGAGCAAAAGCTGATTTCTGAGGAGGATCTATGAAGCTTAAGTCGAC-3'), consisting of a BamHI site, 10 bases of the Dsh $5^{\prime}$ leader sequence immediately upstream of initiation codon of the Dsh cDNA, an NcoI site /containing the initiator ATG codon), an EcoRI site (not present in the Dshcoding sequence), a 30-bp sequence encoding the Myc epitope, a stop codon (TGA), and 12-bp containing HindIII, AfIII, and SalI sites, was cloned as a BamHI-SalI fragment into pBluescript IIKS +

Polymerase chain reaction (PCR) was used for the construction of all Dsh-Myc fusions. Fidelity of the PCR reactions and subsequent cloning steps were confirmed by DNA sequencing. To generate the full-length Dsh-Myc protein and the Myctagged carboxy-terminal deletion mutants D-1 through D-5 (Fig. 6), a 28-base sense primer 15'-TTCCATGGACGCGGACAGGGGCGGCGGG-3'), corresponding to an NcoI site (containing the ATG codon) and amino acids $2-7$ of the Dsh protein, was used in combination with five different antisense primers, each containing an EcoRI site and 21 bases of the Dsh-coding region. To reconstruct full-length Dsh, a primer containing codons $617-623$ of the Dsh cDNA was used. Similarly, primers containing codons $474-480$ were used for the construction of D-1, codons 366-372 for D-2, codons 279-285 for D-3, codons 226-232 for D-4, and codons 109-115 for D-5. To generate two amino-terminal deletion mutants (D-6 and D-7), which both start at internal methionine 166 (Fig. 6), another 28-base sense primer (5'-TTCCATGGGCAATCCGCTGCTGCAGCCG-3') was used in combination with antisense primers to reconstruct full-length Dsh and mutant (D-1). All PCR products were double digested with $\mathrm{NcoI}$ and EcoRI and inserted into the NcoIEcoRI cassette of pBSII-Myc, such that the Dsh-coding sequence was in-frame with the Myc epitope. Becauase of the presence of the EcoRI site, an additional two amino acids (EF) were generated between the Dsh protein sequence and the Myc epitope.
Another mutant (D-dhr, Fig. 6), which lacks about two-thirds of the DHR, was constructed as follows. A PCR product, used to generate mutant D-3, was digested with EcoRI, made bluntended with mung bean nuclease, and digested again with $\mathrm{NcoI}$. The resulting $0.84-\mathrm{kb}$ DNA fragment was ligated to a $3.8-\mathrm{kb}$ NcoI-MscI fragment derived from the full-length Dsh-myc fusion construct. This resulted in a mutant lacking amino acids 286-336. A mutant that lacks a basic domain (D-br, Fig. 6), corresponding to amino acids 215-228 (RLQVRKKPQRRKKR), was constructed as follows: Taking advantage of a NarI site present at codon 229 (just downstream of this basic domain), another antisense primer $\left(5^{\prime}\right.$-ATAGGCGCCTGAACGCTGCTATAGTCGGT-3') was used to create a new NarI site at codon 215. The PCR product encoding amino acids 1-214 was double digested with $N c o I$ and NarI. A $0.65-\mathrm{kb}$ Ncol-NarI fragment thus generated was ligated with a $4.2-\mathrm{kb}$ NcoI-NarI fragment of the full-length Dsh--myc fusion construct (generated by complete $\mathrm{NCOI}$ and partial NarI digestions) creating a mutant lacking only these 14 basic amino acids.

All of the Dsh-myc fusion constructs in Bluescript were double digested with $\mathrm{XbaI}$ and SalI. After Klenow treatment, resulting blunt-ended fragments were inserted into the EcoRV site of vector pMK33 (Koelle et al. 1991).

\section{Cell culture, Wg protein assays, and transfections}

The Drosophila wing imaginal disc cell line cl-8 (Peel and Milner 1992) was cultured in M3 medium of Shields and Sang (Sigma), supplemented with $100 \mathrm{U} / \mathrm{ml}$ of penicillin $/ 100 \mu \mathrm{g} / \mathrm{ml}$ of streptomycin, $2 \%$ heat-inactivated fetal calf serum (FCS) (Sigma), $0.125 \mathrm{IU} / \mathrm{ml}$ of insulin (Sigma), and $2.5 \%$ of a fly extract prepared as described by Currie et al. (1988). Cells were maintained at $25^{\circ} \mathrm{C}$ under air. $\mathrm{S} 2$ cells were grown in $\mathrm{S} 2$ medium (GIBCO) supplemented with $100 \mathrm{U} / \mathrm{ml}$ of penicillin $/ 100 \mu \mathrm{g} / \mathrm{ml}$ of streptomycin and $12.5 \%$ heat inactivated FCS. S2 cells transfected with a construct containing the heat shock promoter driving $\mathrm{Wg}$ expression (S2-HS-wg cells) have been described elsewhere (Cumberledge and Krasnow 1993). Transfections and $\mathrm{Wg}$ protein assays, including antibody depletion experiments, were performed as described in Van Leeuwen et al. (1994). Transfected cell lines were induced to overexpress Dsh by addition of $0.5 \mathrm{mM} \mathrm{CuSO}_{4}$.

\section{Antibody production}

A cDNA fragment encoding amino acids 7-115 of the Dsh protein (region I), was amplified by PCR and cloned into pGEX-2TK (Pharmacia), to create a glutathione $S$-transferase (GST)-Dsh fusion protein. Similarly, a 663-bp PstI-Xhol fragment (Klingensmith et al. 1994), corresponding to amino acids 175-395 (region II), was cloned into the PstI-Sall sites in pATH 11 (Koerner et al. 1991) to create the TrpE-Dsh fusion protein. Both fusion proteins were produced in Escherichia coli strain HB101. Production of the GST-Dsh fusion protein was induced with $0.1 \mathrm{~mm}$ isopropyl- $\beta$-D-thiogalactopyranoside (IPTG) at $37^{\circ} \mathrm{C}$, as described by Smith and Johnson (1988), and fusion protein was purified by SDS-PAGE from crude bacterial lysates. Production of the TrpE-Dsh fusion protein was induced by $20 \mu \mathrm{g} / \mathrm{ml}$ of indolacrylic acid (Sigma) at $30^{\circ} \mathrm{C}$ and purified by SDS-PAGE. Polyclonal antisera against these fusion proteins were raised in rats and rabbits.

\section{Fly stocks and generation of germ-line clones}

Germ-line clones homozygous mutant for the $d s h^{\mathrm{V} 26}$ allele, were generated using the yeast recombinase-based FLP-DTS 
system (Chou and Perrimon 1992) as described (Klingensmith et al. 1994). Homozygous mutant embryos were identified morphologically by a lack of segmentation, apparent at stage 11-12 (Klingensmith et al. 1989). Wild-type embryos (yellow-white) of the same stage were used as controls. To analyze the Dsh modification in HS-wg embryos (Noordermeer et al. 1992), lysates were prepared from 3- to 17-hr-old embryos, $3 \mathrm{hr}$ after heat shock $\left(35 \mathrm{~min}, 37^{\circ} \mathrm{C}\right)$.

\section{Cell lysates and immunoblot analysis}

Cl-8 cells were grown to $80 \%$ confluency, washed with PBS, and lysed in lysis buffer $150 \mathrm{~mm}$ Tris at $\mathrm{pH} 7.5,150 \mathrm{mM} \mathrm{NaCl}, 1 \%$ NP-40, $5 \mathrm{~mm}$ EDTA), supplemented with $20 \mu \mathrm{g}$ of leupeptin, $100 \mu \mathrm{g}$ of aprotinin, and $180 \mu \mathrm{g}$ of $\mathrm{PMSF} / \mathrm{ml}$. An equal volume of sample buffer $(50 \mathrm{~mm}$ Tris at $\mathrm{pH} 6.8,4 \%$ SDS, $10 \% \beta$-mercaptoethanol, $10 \%$ glycerol, $6 \mathrm{~m}$ urea) was added, and samples were boiled for $3 \mathrm{~min}$ prior to loading onto $7.5 \%$ SDS-polyacrylamide gels.

Drosophila embryos, 0-14 hr old, were dechorionated iexcept those shown in Fig. 1C) with $50 \%$ bleach, rinsed with water, and homogenized in lysis buffer containing protease inhibitors. An equal volume of sample buffer was added, and the samples were boiled for $3 \mathrm{~min}$ prior to SDS-PAGE. Western blot analysis was performed exactly as described (Van Leeuwen et al. 1994). The antibodies used for Western blotting include monoclonal anti-Arm antibody N12-7Al (Peifer 1993) at a dilution of 1: 1000; rat-polyclonal anti- $\alpha$-catenin antibody DCAT-1/Oda et al. 1993) diluted 1:1000; monoclonal anti-human c-Myc antibody 9E10 (Oncogene Science), diluted 1:1000; monoclonal anti-phosphotyrosine antibody 4G10 (Upstate Biotechnology), diluted 1:1000; and rat polyclonal anti-Dsh region I antibody (Fig. 1), at a concentration of 1:1000. Peroxidase-conjugated secondary antibodies against mouse IgG (Bio-Rad), rabbit IgG (Bio$\mathrm{Rad}$ ), and rat IgG (Jackson Immuno Research Laboratories) were used at dilutions of 1:20,000.

\section{Immunoprecipitation and phosphatase treatment}

A subconfluent T75 flask of cl-8 cells $\left(\sim 10^{7}\right.$ cells $)$, or $500 \mathrm{em}-$ bryos, were lysed for $10 \mathrm{~min}$ in $1 \mathrm{ml}$ of lysis buffer containing $1 \%$ SDS and $1 \mathrm{~mm}$ sodium vanadate $\left(\mathrm{NaVO}_{3}\right)$. The lysate was boiled for $10 \mathrm{~min}$ and diluted 10 -fold with lysis buffer containing protease inhibitors and $\mathrm{Na}_{3} \mathrm{VO}_{4}$ to reduce the SDS concentration to $0.1 \%$. After centrifugation at $10^{3} \mathrm{rpm}$ for $20 \mathrm{~min}, 30$ $\mu l$ of rabbit anti-Dsh region II antiserum was added to the supernatant and incubated at $4^{\circ} \mathrm{C}$ overnight. The immunocomplex was precipitated with $25 \mu \mathrm{l}$ of protein A-Sepharose beads (Pharmacia), washed three times with lysis buffer containing $\mathrm{Na}_{3} \mathrm{VO}_{4}$, and taken up in SDS-sample buffer. Alternatively, Dsh immunoprecipitates were washed with PAP buffer $140 \mathrm{mM}$ MOPS at $\mathrm{pH} 5.5,1 \mathrm{mM} \mathrm{MgCl}_{2}, 50 \mathrm{mM} \mathrm{NaCl}, 1 \mathrm{mM}$ PMSF/ or PTP buffer [20 mM Tris at pH 7.2, $150 \mathrm{~mm} \mathrm{NaCl}, 0.1 \%$ (vol/vol) 2-mercapto-ethanol, $10 \mathrm{mg} / \mathrm{ml}$ of BSA, $1 \mathrm{mM} \mathrm{PMSF}$. Immunocomplexes were then treated with 0.3 units of PAP (Sigma) in 50 $\mu \mathrm{l}$ of PAP buffer for $3 \mathrm{hr}$ at $37^{\circ} \mathrm{C}$ or with 0.016 units of PTP (34-kD fragment; Boehringer Mannheim) in $30 \mu$ l of PTP buffer for $2 \mathrm{hr}$ at $37^{\circ} \mathrm{C}$. Immunocomplexes were taken up in SDSsample buffer, boiled, and separated on SDS-polyacrylamide gels. Dsh protein was detected by Western blotting.

\section{Cell fractionation}

Two subconfluent T75 flasks of cl-8 cells, incubated for $2 \mathrm{hr}$ in the presence or absence of $\mathrm{S} 2$ cells overproducing $\mathrm{Wg}$, were washed twice with PBS, scraped, and collected by low speed centrifugation. Cells were resuspended in hypotonic buffer (10 $\mathrm{mm}$ Tris, $0.2 \mathrm{~mm} \mathrm{MgCl}_{2}$ ( $\mathrm{pH} 7.4$ ), supplemented with protease inhibitors, and phosphatase inhibitors; $0.5 \mu \mathrm{M}$ microcystin (GIBCO), and $1 \mathrm{~mm} \mathrm{Na} 3 \mathrm{VO}_{4}$ ]. After a $10 \mathrm{~min}$ incubation on ice, the cells were disrupted by 25 strokes in a Dounce homogenizer (tight-fitting pestle). The homogenate was adjusted to a final concentration of $0.25 \mathrm{M}$ sucrose and $1 \mathrm{~mm}$ EDTA. An aliquot of the homogenate was kept for later analysis. The homogenate was centrifuged at $1500 \mathrm{~g}$ for $10 \mathrm{~min}$ at $4^{\circ} \mathrm{C}$. The supernatant fraction was removed, the pellet resuspended in the same buffer, and pelleted again. The two supernatants were combined and centrifuged at $100,000 \mathrm{~g}$ for $1 \mathrm{hr}$ at $4^{\circ} \mathrm{C}$ in a SW55 Ti rotor (Beckman Instruments). The supernatant was removed and kept at $4^{\circ} \mathrm{C}$. The pellet was resuspended in the same buffer and pelleted again at $100,000 \mathrm{~g}$. The two supernatants, denoted S100, were pooled and protein in these fractions was precipitated by adding an equal volume of $20 \%$ TCA. Precipitates were collected by centrifugation, neutralized with a $1 \mathrm{M}$ Tris-base solution, and resuspended in lysis buffer containing protease and phosphatase inhibitors. The membrane pellet was resuspended in an equal volume of lysis buffer and incubated on ice for $10 \mathrm{~min}$. This homogenate was centrifuged for $10 \mathrm{~min}$ at $10,000 \mathrm{rpm}$. The supernatant, denoted P100 (soluble), was collected. The pellet was extracted once more and centrifuged again. This insoluble pellet (P100 insoluble), was resuspended in the same volume of lysis buffer. An equal volume of SDS-sample buffer was added to all fractions, and the samples were boiled for 10 minutes.

\section{Immunohistochemistry and confocal microscopy}

Embryos were dechorionated in $50 \%$ bleach and fixed in $4 \%$ paraformaldehyde in PBS/heptane for $15 \mathrm{~min}$, followed by devitellinization in methanol. Embryos were washed three times for 15 min each, first in PBS, $0.3 \%$ Triton X-100 and then in PBS alone. After blocking in $2 \%$ goat serum in PBS for $1 \mathrm{hr}$, embryos were incubated at $4^{\circ} \mathrm{C}$ overnight with rat anti-Dsh region $\mathrm{I}$, diluted 1:250 in PBS, 2\% goat serum. After washing in PBS, cmbryos were incubated in FITC-conjugated secondary antibody (Sigma), 1:64 in PBS plus 2\% goat serum. Finally, embryos were washed in PBS and mounted in Vectashield mounting medium (Vector).

Cells grown on two-well chamber slides were fixed in $4 \%$ paraformaldehyde, PBS, for $15 \mathrm{~min}$ and permeabilized in PBS, $0.3 \%$ Triton $\mathrm{X} 100$, for $15 \mathrm{~min}$. Subsequent washes and antibody incubations were done in the same way as described for embryos. Confocal images were collected with a Bio-Rad MRC 1000 confocal laser setup attached to a Zeiss Axioscope microscope.

\section{Acknowledgments}

We thank Dr. Jim Ferrell and members of our laboratory, particularly Harsh Thaker, for helpful discussion and comments on the manuscript. Ken Cadigan and Jasprien Noordermeer gave useful advice and help in generating mutant embryo collections. Antibodies and Drosophila mutant stocks were kindly provided by Drs. Mark Peifer, Norbert Perrimon, and Masatoshi Takeichi. A.W. is supported by a fellowship from the Deutsche Forschungsgemeinschaft. These studies were supported by the Howard Hughes Medical Institute, of which R.N. is an investigator.

The publication costs of this article were defrayed in part by payment of page charges. This article must therefore be hereby marked "advertisement" in accordance with 18 USC section 1734 solely to indicate this fact. 


\section{References}

Aronheim, A., D. Engelberg, N. Li, N. Al-Alawi, J. Schlessinger, and M. Karin. 1994. Membrane targeting of the nucleotide exchange factor Sos is sufficient for activating the Ras signaling pathway. Cell 78: 949-961.

Baker, N.E. 1988. Embryonic and imaginal requirements for wingless, a segment-polarity gene in Drosophila. Dev. Biol. 125: 96-108.

Bejsovec, A. and A. Martinez-Arias. 1991. Roles of wingless in patterning the larval epidermis of Drosophila. Development 113: $471-485$.

Bourouis, M., P. Moore, L. Ruel, Y. Grau, P. Heitzler, and P. Simpson. 1990. An early embryonic product of the gene shaggy encodes a serine/threonine protein kinase related to the CDC28/cdc2 ${ }^{+}$subfamily, EMBO I. 9: 2877-2884.

Bryant, P. and D. Woods. 1992. Letter to the editor. Cell 68: 621-622.

Campos-Ortega, J.A. and V. Hartenstein. 1985. The embryonic development of Drosophila melanogaster. Springer-Verlag, Berlin, Germany.

Cho, K., C. Hunt, and M. Kennedy. 1992. The rat brain postsynaptic density fraction contains a homolog of the Drosophila discs-large tumor suppressor protein. Neuron 9: 929-942.

Chou, T.B. and N. Perrimon. 1992. Use of a yeast site-specific recombinase to produce female germline chimeras in Drosophila. Genetics 131: 643-653.

Cohen, S.M. 1990. Specification of limb development in the Drosophila embryo by positional cues from segmentation genes. Nature 343: 173-177.

Cumberledge, S. and M.A. Krasnow. 1993. Intercellular signalling in Drosophila segment formation reconstructed in vitro. Nature 363: 549-552.

Currie, D.A., M.J. Milner, and C.W. Evans. 1988. The growth and differentiation in vitro of $\mathrm{leg}$ and wing imaginal disc cells from Drosophila melanogaster. Development 102: 804-814

Diaz-Benjumea, F.J. and S.M. Cohen. 1994. wingless acts through the shaggy/zeste-white 3 kinase to direct dorsalventral axis formation in the Drosophila leg. Development 120: $1661-1670$.

Dougan, S. and S. Dinardo. 1992. Drosophila wingless generates cell type diversity among engrailed expressing cells. Nature 360: $347-350$

Egan, S.E. and R.A. Weinberg. 1993. The pathway to signal achievement. Nature 365: 781-783.

Evan, G.I., G.K. Lewis, G. Ramsay, and J.M. Bishop. 1985. Isolation of monoclonal antibodies specific for human c-myc proto-oncogene product. Mol. Cell. Biol. 5: 3610-3616.

Gale, N.W., S. Kaplan, E.J. Lowenstein, J. Schlessinger, and D. Bar-Sagi. 1993. Grb2 mediates the EGF-dependent activation of guanine nucleotide exhange on Ras. Nature 363: 88-92.

Greenwald, I. and G.M. Rubin. 1992. Making a difference: The role of cell-cell interactions in establishing separate identities for equivalent cells. Cell 68: 271-281.

Kaphingst, K. and S. Kunes. 1994. Pattern formation in the visual centers of the Drosophila brain: Wingless acts via decapentaplegic to specify the dorsoventral axis. Cell 78: 437448.

Klingensmith, J. and R. Nusse. 1994. Signaling by wingless in Drosophila. Dev. Biol. 166: 396-414.

Klingensmith, J. and N. Perrimon. 1991. Segment polarity genes and intercellular communication in Drosophila. In Cell activation: Genetic approaches (ed. J.J. Mond, J.C. Cambier, and A. Weiss), pp. 251-274. Raven Press, New York.

Klingensmith, J., E. Noll, and N. Perrimon. 1989. The segment polarity phenotype of Drosophila involves differential tendencies toward transformation and cell death. Dev. Biol. 134: 130-145.

Klingensmith, J., R. Nusse, and N. Perrimon. 1994. The Drosophila segment polarity gene dishevelled encodes a novel protein required for response to the wingless signal. Genes \& Dev. 8: 118-130.

Koelle, M.R., W.S. Talbot, W.A. Segraves, M.T. Bender, P. Cherbas, and D.S. Hogness. 1991. The Drosophila EcR gene encodes an ecdysone receptor, a new member of the steroid receptor superfamily. Cell 67: 59-77.

Koerner, T.J., J.E. Hill, A.M. Myers, and A. Tzagoloff. 1991. High-expression vectors with multiple cloning sites for construction of trpE fusion genes; path vectors. Methods Enzymol. 194: 477-490.

McCormick, F. 1993. Signal transduction: How receptors turn Ras on. Nature 363: 15-16.

Noordermeer, J., P. Johnston, F. Rijsewijk, R. Nusse, and P. Lawrence. 1992. The consequences of ubiquitous expression of the wingless gene in the Drosophila embryo. Development 116: 711-719.

Noordermeer, J., J. Klingensmith, N. Perrimon, and R. Nusse. 1994. dishevelled and armadillo act in the wingless signalling pathway in Drosophila. Nature 367: 80-83.

Nusse, R. and H.E. Varmus. 1992. Wnt genes. Cell 69: 10731087.

Oda, H., T. Uemura, K. Shiomi, A. Nagafuchi, S. Tsukita, and M. Takeichi. 1993. Identification of a Drosophila homologue of $\alpha$-catenin and its association with the armadillo protein. I. Cell Biol. 121: 1133-1140.

Peel, D.J. and M.J. Milner. 1992. The expression of PS integrins in Drosophila melanogaster imaginal disc cell lines. Wilhelm Roux's Arch. Dev. Biol. 201: 120-123.

Peifer, M. 1993. The product of the Drosophila segment polarity gene armadillo is part of a multi-protein complex resembling the vertebrate adherens junction. I. Cell Sci. 105: 9931000 .

Peifer, M., L.-M. Pai, and M. Casey. 1994a. Phosphorylation of the Drosophila adherens junction protein armadillo; roles for wingless signal and zeste-whte 3 kinase. Dev. Biol. 166: 543-566.

Peifer, M., D. Sweeton, M. Casey, and E. Wieschaus. 1994b. wingless signal and zeste-white 3 kinase trigger opposing changes in the intracellular distribution of armadillo. Development 120: 369-380.

Perrimon, N. 1994. The genetic basis of patterned boldness in Drosophila. Cell 76: 781-784.

Perrimon, N. and A.P. Mahowald. 1987. Multiple functions of segment polarity genes in Drosophila. Dev. Biol. 119: 587600.

Riggleman, B., P. Schedl, and E. Wieschaus. 1990. Spatial expression of the Drosophila segment polarity gene armadillo is post-transcriptionally regulated by wingless. Cell 63: 549560.

Rijsewijk, F., M. Schuermann, E. Wagenaar, P. Parren, D. Weigel, and R. Nusse. 1987. The Drosophila homolog of the mouse mammary oncogene int- 1 is identical to the segment polarity gene wingless. Cell 50: 649-657.

Rubinfeld, B., B. Souza, I. Albert, O. Müller, S.H. Chamberlain, F.R. Masiarz, S. Munemitsu, and P. Polakis. 1993. Association of the $A P C$ gene product with $\beta$-catenin. Science 262: 173l-1734.

Siegfried, E., L.A. Perkins, T.M. Capaci, and N. Perrimon. 1990. Putative protein kinase product of the Drosophila segmentpolarity gene zeste-white 3. Nature 345: 825-829.

Siegfried, E., T.B. Chou, and N. Perrimon. 1992. wingless sig- 
naling acts through zeste-white 3 , the Drosophila homolog of glycogen synthase kinase-3, to regulate engrailed and establish cell fate. Cell 71: 1167-1179.

Siegfried, E., E. Wilder, and N. Perrimon. 1994. Components of wingless signalling in Drosophila. Nature 367: 76-80.

Smith, D.B. and K.S. Johnson. 1988. Single-step purification of polypeptides expressed in Escherichia coli as fusions with glutathione $S$-transferase. Gene 67: 31-40.

Sternberg, P. 1993. Intercellular signaling and signal transduction in C. elegans. Annu. Rev. Genet. 27: 497-521.

Stokoe, D., S.G. Macdonald, K. Cadwallader, M. Symons, and J.F. Hancock. 1994. Activation of Raf as a result of recruitment to the plasma membrane. Science 264: 1463-1467.

Struhl, G. and K. Basler. 1993. Organizing activity of wingless protein in Drosophila. Cell 72: 527-540.

$\mathrm{Su}, \mathrm{L} .-\mathrm{K} ., \mathrm{B}$. Vogelstein, and K.W. Kinzler. 1993. Association of the APC tumor suppressor protein with catenins. Science 262: 1734-1737.

Sussman, D., J. Klingensmith, P. Salinas, P. Adams, R. Nusse, and N. Perrimon. 1994. Isolation and characterization of a mouse homolog of the Drosophila segment polarity gene dishevelled. Dev. Biol. 166: 73-86.

Theisen, H., J. Purcell, M. Bennett, D. Kansagara, A. Syed, and J. Marsh. 1994. dishevelled is required during wingless signaling to establish both cell polarity and cell identity. Development 120: 347-360.

van den Heuvel, M., C. Harryman-Samos, J. Klingensmith, N. Perrimon, and R. Nusse. 1993. Mutations in the segment polarity genes wingless and porcupine impair secretion of the wingless protein. EMBO J. 12: 529.3-5302.

Van Leeuwen, F., C. Harryman Samos, and R. Nusse. 1994. Biological activity of soluble wingless protein in cultured Drosophila imaginal disc cells. Nature 368: 342-344.

Woods, D.F. and P.J. Bryant. 1991. The discs-large tumor suppressor gene of Drosophila encodes a guanylate kinase homolog localized at septate junctions. Cell 66: 451-464. 


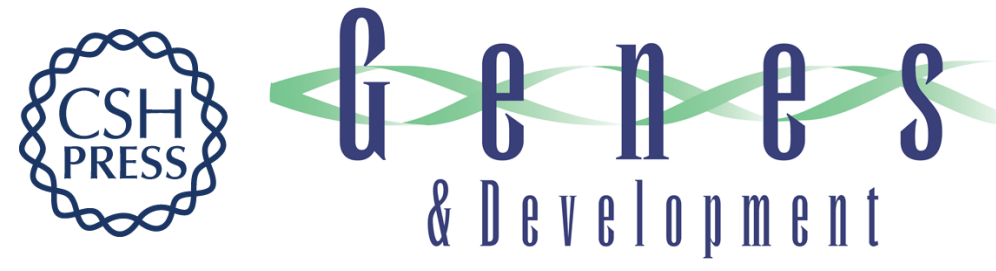

\section{The dishevelled protein is modified by wingless signaling in Drosophila.}

S Yanagawa, F van Leeuwen, A Wodarz, et al.

Genes Dev. 1995, 9:

Access the most recent version at doi:10.1101/gad.9.9.1087

References This article cites 49 articles, 13 of which can be accessed free at: http://genesdev.cshlp.org/content/9/9/1087.full.html\#ref-list-1

License

Email Alerting Receive free email alerts when new articles cite this article - sign up in the box at the top Service right corner of the article or click here.

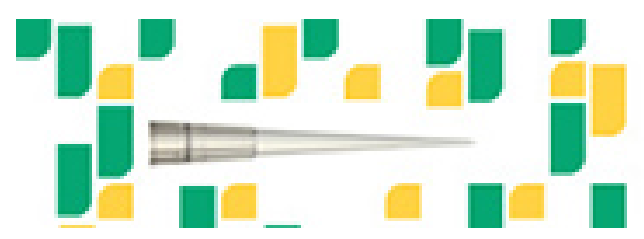

Focused on your science.

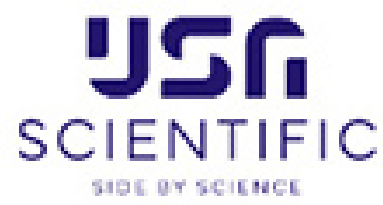

Copyright (c) Cold Spring Harbor Laboratory Press 